\title{
Análise das estratégias de produção de seis montadoras de motores para automóveis
}

\section{Operations strategies of automobile engine assembly companies}

\author{
Alceu Gomes Alves Filho' \\ Edemilson Nogueira ${ }^{1}$ \\ Paulo Eduardo Gomes Bento' 1
}

\begin{abstract}
Resumo: São identificadas e analisadas neste artigo as Estratégias de Produção (EP) adotadas, durante o período 2005-2006, por 6 empresas montadoras de motores para automóveis instaladas no Brasil. Três delas instalaram-se há várias décadas no País e são aqui denominadas "estabelecidas"; as outras três, apenas há alguns anos, são denominadas "entrantes". Para o levantamento de informações sobre as EPs adotadas, entrevistas semiestruturadas foram feitas com pelo menos um dos principais responsáveis - gerentes - pela unidade produtora de motores em cada empresa. Observou-se que as EPs adotadas pelas empresas são distintas entre os grupos e em cada grupo (intragrupos), marcadas por diferenças nas áreas de decisão estruturais, apesar de haver semelhanças entre as estratégias competitivas das empresas em cada grupo (estabelecidas e entrantes). Alguns dos resultados encontrados nesta pesquisa confirmam proposições da literatura, outros indicam que há temas que precisam ainda ser cuidadosamente investigados.
\end{abstract}

Palavras-chave: Estratégia de produção. Prioridades competitivas. Montadoras de motores.

\begin{abstract}
The operations strategies adopted by six engine assemblers between 2005 and 2006 in Brazil were identified and analyzed. Three of them started their operations some decades ago and were, therefore, denominated "established firms". The other three have started their operations only after the 1990s and were denominated "entrant firms". Information on the adopted strategies was gathered through interviews with at least one of the main managers in each engine assembly plant investigated. We observed that the adopted operations strategies are different in terms of inter and intra groups of those plants. The distinct characteristics of operations strategies are mainly due to differences in structural decision areas although the competitive strategies in each group have some common traces.
\end{abstract}

Keywords: Operations strategies. Competitive priorities. Engine assemblers.

\section{Introdução}

No final dos anos sessenta, Skinner (1969) já chamava a atenção para a importância da função produção e de seu papel estratégico na organização. Desde meados da década de 1990, no Brasil e no mundo, modificações no ambiente econômico alteraram de forma significativa os padrões de concorrência em diversos setores industriais e em particular na indústria automobilística e de autopeças. Dentre as principais alterações podem-se mencionar os movimentos de terceirização das montadoras, de reorganização do setor de autopeças e das cadeias de suprimentos. Ocorreram o fortalecimento dos fornecedores chamados sistemistas, a busca de fornecedores em qualquer região do mundo com o global sourcing, a instalação de fornecedores multinacionais de grande porte em diversos países com o follow sourcing, a ampliação da participação tanto na oferta (pela instalação de plantas montadoras) como no consumo de países do leste europeu e da China, a difusão do modelo de produção japonês ou da produção enxuta e, ainda, a diversificação de modelos de automóveis, com a combinação de plataformas mundiais e modelos de automóveis específicos lançados em cada mercado. No Brasil, observou-se, além disso, a entrada (instalação de unidades de produção) de algumas empresas montadoras de automóveis, um movimento de desnacionalização de grandes empresas de autopeças locais, a modernização das plantas, a ampliação da capacidade instalada de produção e a desconcentração geográfica com a instalação de unidades de produção (greenfields) em locais com pouca tradição na produção de automóveis ou de seus componentes, favorecida em parte pelos

\footnotetext{
${ }^{1}$ Departamento de Engenharia de Produção, Universidade Federal de São Carlos - UFSCar, Rod. Washington Luís, Km 235, CEP 13565-905, São Carlos, SP, e-mail: alceu@dep.ufscar.br; edn@dep.ufscar.br; paulobento@dep.ufscar.br
} 
subsídios concedidos pelos governos estaduais no que ficou conhecido como "guerra fiscal".

Nesse contexto, no Brasil e no mundo, e em diversos segmentos industriais, poder-se-ia esperar que as empresas despendessem esforços para formulação de novas estratégias competitivas e para desenvolvimento de políticas compatíveis em suas áreas funcionais de modo a fazer frente à concorrência nos diferentes segmentos de mercado. De acordo com Hill (2000), diante das pressões impostas pelo aumento da competição, as empresas têm necessidade urgente de coordenar as atividades de suas principais funções como parte de uma estratégia coerente. Porém, ainda segundo Hill (2000), na prática, muitas empresas não fazem isso, pois não reúnem as ideias e contribuições funcionais que as auxiliariam a identificar, selecionar e harmonizar direções estratégicas. No mesmo sentido, Slack (1993, p. 13) afirma que

[...] muitas empresas conhecem a frustração de ver suas melhores ambições estratégicas renderem-se impotentes à inabilidade da Manufatura de traduzi-las em formas de ação efetiva. [...] A estratégia competitiva não pode esperar ter sucesso a longo prazo, a menos que considere que o papel da Manufatura na criação da vantagem estratégica seja tanto direto quanto central.

A manufatura ou a função produção pode ter um papel decisivo no desenvolvimento de uma posição competitiva favorável para as empresas. E por isso, é relevante o desenvolvimento de pesquisas sobre o papel estratégico da função produção. Neste artigo são apresentados os resultados de uma pesquisa realizada em 2006 e financiada pelo CNPq, em que as Estratégias de Produção (EPs) de seis plantas dedicadas à produção de motores - pertencentes a seis das sete empresas automobilísticas que então possuíam unidades produtoras de motores para automóveis instaladas no Brasil - foram identificadas e analisadas.

Tais montadoras de motores e de automóveis adotaram, ao longo do tempo, como se verá posteriormente neste artigo, diferentes decisões nas áreas estruturais e infraestruturais da produção, configurando trajetórias produtivas distintas, associadas aos seus posicionamentos e perspectivas de crescimento no mercado brasileiro de automóveis.

As principais diferenças entre as EPs das seis empresas podem ser atribuídas aos momentos de entrada no mercado, às estratégias de entrada, às condições de concorrência e exigências do mercado e às próprias sequências de decisões implementadas nas áreas estruturais e infraestruturais da produção. Neste artigo procura-se apresentar algumas das principais decisões tomadas, proporcionando ainda uma comparação entre as trajetórias recentes (que antecedem o momento da pesquisa) seguidas pelas seis empresas.

O texto a seguir está estruturado em quatro seções. A seção dois traz o referencial teórico a respeito de estratégia de produção adotado na pesquisa. Em seguida, na seção três, é abordado o método utilizado na pesquisa de campo e, na seção quatro, são apresentados os resultados obtidos e as análises elaboradas. Finalmente, nas considerações finais, são sumarizadas as principais conclusões e possibilidades de estudos futuros.

\section{Estratégia de produção}

A estratégia de produção (EP) começou a ser investigada sistematicamente a partir de meados da década de 1980, cerca de uma década e meia após a publicação da importante contribuição inicial de Skinner (1969). Segundo este autor:

A manufatura [ou a produção] é parte do conceito estratégico que relaciona as forças e os recursos da empresa às oportunidades no mercado. Cada estratégia cria uma única tarefa para a manufatura (SKINNER, 1969, p. 140).

Ao longo do tempo, diversas definições para EP foram propostas, refletindo diferentes linhas de pensamento sobre o planejamento estratégico empresarial e destacando aspectos escolhidos da gestão de operações como, por exemplo, Cohen e Lee (1985), Swamidass e Newell (1987), Anderson, Cleveland e Schroeder (1989), Hayes e Pisano (1994), Mills, Platts e Gregory (1995), Gyanpah e Boye (2001), Säfsten, Winroth e Stahre (2007) e Skinner (1985, 1996, 2007). Neste trabalho, emprega-se um conjunto de conceitos tradicionais sobre o assunto, escolhido em função da proposta de pesquisa definida e aqui relatada.

A definição proposta por Hayes et al. (2005), a seguir apresentada, é aqui adotada porque incorpora a perspectiva da VBR (Visão Baseada em Recursos) e é também compatível com o conceito de estratégia como "padrão" apresentado por Mintzberg (1988). Segundo esse autor,

[...] a estratégia como padrão refere-se ao [...] comportamento resultante, as estratégias realmente adotadas por meio daquelas ações. [...] Estratégia é um padrão, especificamente um padrão em um curso de ações. [...] Em outras palavras, por esta definição, estratégia é consistência em comportamento, seja ele pretendido ou não. (MINTZBERG, 1988, p. 14).

De acordo com Hayes,

[...] a estratégia de produção é um conjunto de objetivos, políticas e restrições autoimpostas que conjuntamente descrevem como a organização se 
propõe a dirigir e desenvolver todos os recursos investidos nas operações, de forma a melhor cumprir (e possivelmente redefinir) sua missão. (HAYES et al., 2005, p. 33).

As recentes revisões de literatura sobre EP (DANGAYACH; DESHMUKH, 2001; BOYER; SWINK; ROSENZWEIG, 2005) confirmam as duas alternativas principais quanto aos focos das pesquisas realizadas: o conteúdo da EP ou o processo de formulação e implementação da EP. Segundo Adamides e Pomonis (2009), na literatura acadêmica, assim como na prática, existe um consenso no que diz respeito ao que constitui o conteúdo da estratégia de produção. Para Boyer, Swink e Rosenzweig (2005, p. 443),

[...] pesquisas focadas em conteúdo referem-se ao estudo das prioridades competitivas e capacidades das operações (da produção) bem como das escolhas e configurações estruturais [...] e infraestruturais.

Para Hayes et al. (2005, p. 42), enquanto as decisões estruturais focalizam os atributos físicos da organização, como a capacidade de produção da planta, as escolhas infraestruturais referem-se aos

[...] sistemas, políticas e práticas que determinam como os aspectos estruturais da organização devem ser gerenciados.

Segundo Dangayach e Deshmukh (2001, p. 887), artigos que abordaram o conteúdo da EP consideraram

[...] capacidades da manufatura, escolhas estratégicas, melhores práticas, comparações transnacionais, revisões de literatura e literatura sobre Estratégia de Manufatura relacionada à medição de desempenho[...] Pesquisas focadas em processo referem-se ao estudo da tomada e desenvolvimento de decisões estratégicas, à comunicação das decisões estratégicas dentro da organização e à implementação da estratégia" (BOYER; SWINK; ROSENZWEIG, 2005, p. 443).

Ou, conforme Dangayach e Deshmukh (2001, p. 887), "Processo é um padrão ou procedimento no qual a EP é desenvolvida e implementada."

Em cada uma dessas alternativas - conteúdo ou processo -, diversos temas ou problemas foram abordados pela literatura, mas ambas apoiam-se em uma estrutura conceitual comum que considera a EP como uma estratégia funcional, formada por prioridades competitivas e por áreas (estruturais e infraestruturais) de decisão da produção. Articulada a outras estratégias funcionais como pesquisa e desenvolvimento, marketing e finanças, a EP deve sustentar a estratégia competitiva da empresa (WHEELWRIGHT, 1984).

Dangayach e Deshmukh (2001) e Boyer, Swink e Rosenzweig (2005) referem-se indistintamente a prioridades competitivas ou a capacidades (capabilities):

"Capacidades da Manufatura: incluem literatura sobre prioridades competitivas, isto é, custo, qualidade, entrega, flexibilidade, etc." (DANGAYACH; DESHMUKH, 2001, p. 904). "Capacidades de Produção podem ser obtidas por meio do alinhamento destas prioridades competitivas com as exigências do Mercado." (KERR; GREENHALGH, 1991 apud DANGAYACH; DESHMUKH, 2001, p. 906).

Mas, observa-se que o termo capacidades deve indicar aquilo que fornece de fato vantagens competitivas às empresas. As prioridades adotadas em determinado período não são, necessariamente, e não devem ser confundidas com vantagens competitivas já alcançadas. Uma empresa pode, por exemplo, priorizar a dimensão custo, e suas vantagens competitivas estarem assentadas, nesse momento, sobre outras dimensões (como qualidade e flexibilidade, por exemplo), ou mesmo pode priorizar a dimensão custo visando conquistar (no futuro) a liderança em custo em sua área de atuação.

Na literatura sobre administração estratégica, o próprio conceito de capacidade tem um significado [flavour] sistêmico. Amit e Schoemaker (1993) sugerem, por exemplo, que capacidades baseiam-se em processos organizacionais que são desenvolvidos ao longo do tempo por meio de interações complexas entre recursos da firma. (MOLLONA, 2002, p. 94).

Segundo Coriat e Dosi (2002, p. 283),

[...] uma grande corporação bem-sucedida obtém força competitiva a partir de sua excelência em um pequeno número de conjuntos de capacidades que podem sustentar uma posição de liderança ao longo do tempo.

Ao tratarem do conteúdo da EP, Hayes, Wheelwrigh e Clark (1988) e Hayes et al. (2005) a compreendem como o conjunto das prioridades competitivas da produção (custo, qualidade, entrega [dependability] e flexibilidade) e das decisões tomadas nas áreas estruturais (capacidade, suprimentos e integração vertical, instalações, tecnologia de processo e de informação) e infraestruturais (sistemas de alocação de recursos e orçamento de capital, sistemas de recursos humanos, sistemas de planejamento e controle da produção, sistemas da qualidade, sistemas de medição de desempenho e recompensa, sistemas de desenvolvimento de produto e processo, organização) da produção. Há, entretanto, na literatura, variações acerca de quais prioridades e quais áreas de decisão 
devam ser examinadas. A Tabela 1 ilustra proposições de alguns dos principais estudiosos do tema a respeito das prioridades competitivas e das áreas de decisão. Estas áreas de decisão foram organizadas como estruturais ou infraestruturais, segundo a proposição de Hayes e Wheelwright (1984), embora alguns dos autores citados não tenham utilizado tal classificação.

Dangayach e Deshmukh (2001, p. 908) afirmam que

A filosofia das escolhas estratégicas é baseada na necessidade [da empresa] atingir consistência interna e externa.

A falta de consistência pode conduzir à perda de participação de mercado.

Neste trabalho, serão consideradas, com algumas adaptações, as prioridades e áreas de decisão apresentadas na Figura 1. Cabe ressaltar que serão analisadas apenas questões relacionadas ao conteúdo das EPs de algumas empresas do setor automotivo brasileiro.

A abordagem tradicional de EP pode ser complementada pela de processos de negócios, contribuindo para uma melhor identificação e compreensão da estratégia de produção - bem como de outros tipos de estratégias. Normalmente não mencionados pelos autores no campo da estratégia de produção, os processos de negócios internos à produção ou que "atravessam" a função produção (e demais funções na empresa) e as fronteiras da firma podem ter impacto significativo nas prioridades competitivas. Podem também auxiliar a caracterização detalhada da estratégia de produção de uma empresa e evidenciar a importância das relações e interfaces da EP com outras estratégias funcionais e da empresa com seus clientes e fornecedores.

Os elementos mais importantes, portanto, relacionados ao conteúdo de uma estratégia de produção são:

- as prioridades ou dimensões competitivas: são as prioridades da função produção, definidas de acordo com a estratégia competitiva e com as competências acumuladas na função;

- as áreas de decisão ou categorias de decisão: são as principais áreas de decisão incluídas na produção e que irão estabelecer a configuração ( $\mathrm{e}$ eventuais modificações) do sistema de produção de acordo com as prioridades escolhidas a curto, médio e longo prazos; e

- os processos de negócios na produção: os conjuntos de sequências de atividades que atravessam a função produção e que também devem ser avaliados no processo de planejamento estratégico, pois, como as áreas de decisão, têm impacto importante no funcionamento e desempenho do sistema de produção.
O conteúdo de uma estratégia de produção, contemplando prioridades, áreas de decisão e processos de negócios, está ilustrado na Figura 1. As prioridades competitivas e as áreas de decisão mencionadas na figura foram propostas, respectivamente, por Garvin (1993) e por Hayes e Wheelwright (1984).

De acordo com Garvin (1998), na abordagem dos processos organizacionais como processos de trabalho (work processes), os processos podem ser subdivididos em operacionais e administrativos. Os operacionais são aqueles que criam, produzem e distribuem os produtos e serviços que os clientes desejam. Os processos administrativos não geram produtos ou serviços aos clientes, mas são necessários para que os processos operacionais se realizem de maneira eficaz. Desenvolvimento de novos produtos, processos de produção e logística constituem exemplos de processos operacionais, enquanto planejamento estratégico, orçamento e sistemas de medição de desempenho são processos administrativos.

Segundo o American Productivity \& Quality Center (2008), os processos se dividem em processos operacionais e em processos administrativos e de suporte. Os operacionais incluem: Entendimento do mercado e dos clientes; Desenvolvimento da visão e da estratégia; Projeto de produtos e serviços; Desenvolvimento da estratégia de marketing e de vendas; Produção e entrega dos produtos e/ou serviços; Emissão de faturas e prestação de serviços pós-venda. Já os processos administrativos e de suporte são: Desenvolvimento e administração de recursos humanos; Administração de informações; Administração financeira e de recursos físicos; Gestão ambiental; Gestão de relações externas; Administração de melhorias e mudanças.

\section{Método de pesquisa}

O método de múltiplos casos foi escolhido para a realização da pesquisa de campo neste estudo. Procurou-se inicialmente realizar a pesquisa em todas as 7 empresas que, em 2006, possuíam plantas dedicadas à montagem de motores para automóveis de passeio. Seis (6), das 7 empresas, concordaram em participar da pesquisa.

Os dados e as informações foram obtidos a partir de entrevistas semiestruturadas, observação direta e consulta a fontes de dados secundárias. As entrevistas, realizadas com gerentes de produção das plantas e de áreas correlatas, foram conduzidas a partir da utilização de um roteiro previamente elaborado, contendo questões abertas e fechadas, visando obter informações a respeito das características gerais das empresas, das prioridades competitivas de produção, dos elementos de gestão da produção relacionados às áreas de decisão estrutural e infraestrutural, dos processos de negócios e dos programas e ações implementados. 


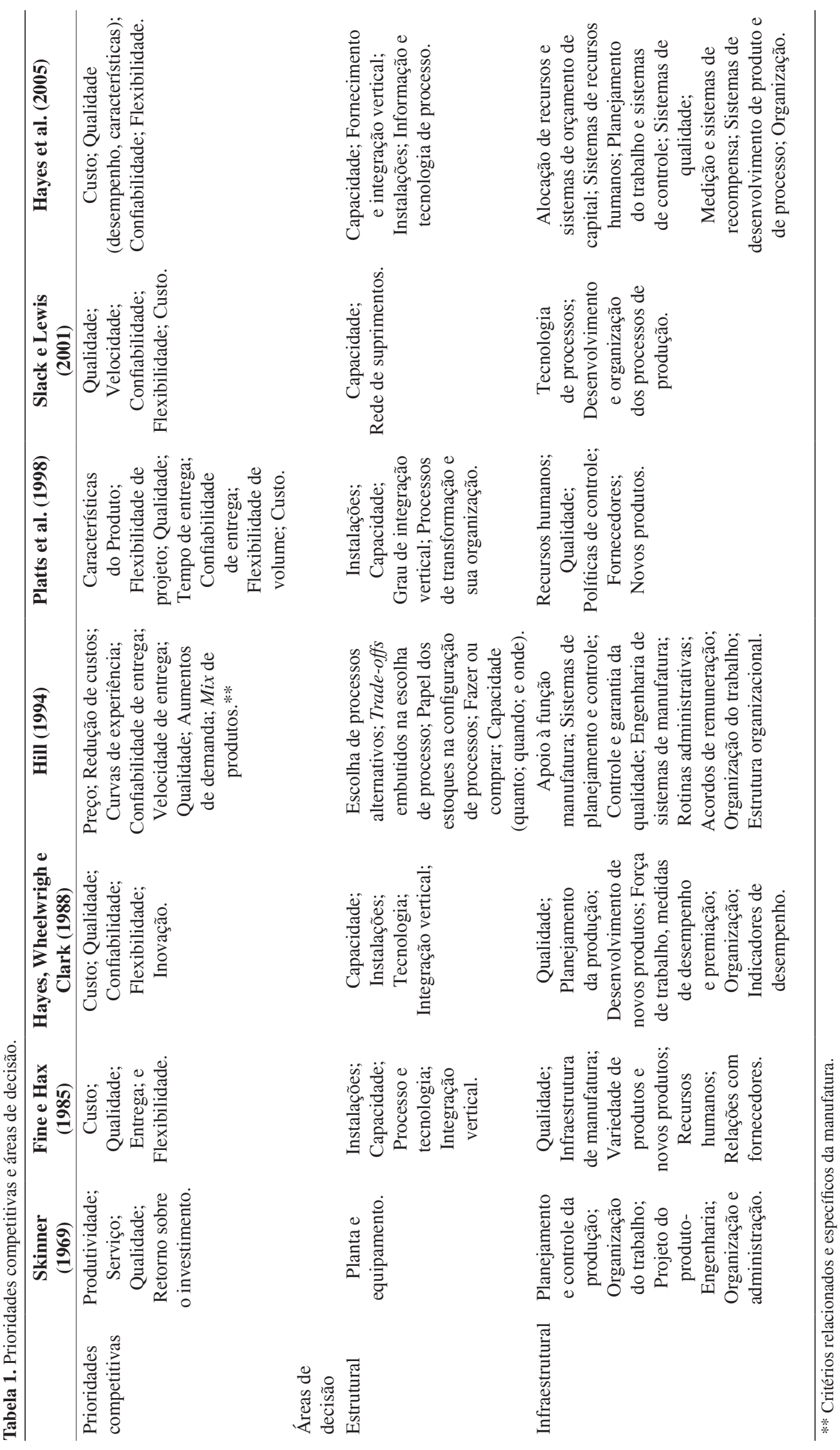



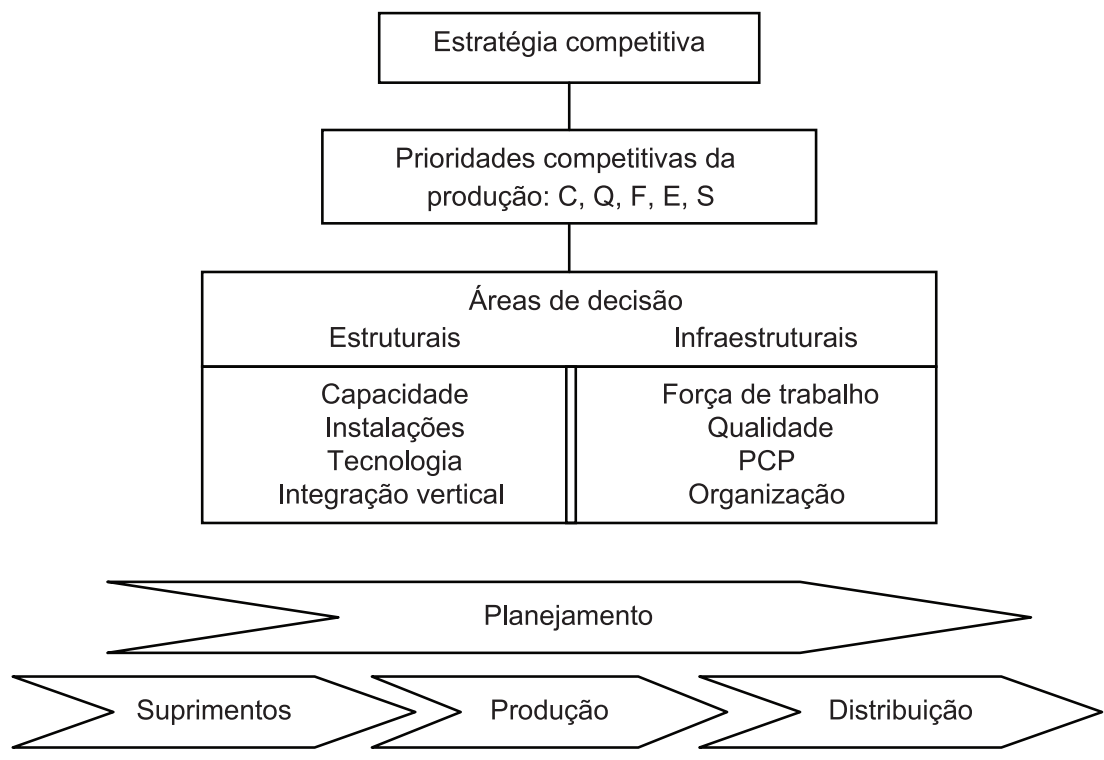

Figura 1. Prioridades competitivas e áreas de decisão. Adaptada de: Hörte, Lindberg e Tunälv (1987).

Em cada uma das 6 empresas, foi entrevistado pelo menos 1 gerente de produção, sendo que, em duas das maiores empresas, foram entrevistados gerentes de diversas áreas ligadas à produção (como desenvolvimento de produto, qualidade, logística). As questões relacionadas à EP, nesse roteiro, tiveram por finalidade a apreensão de possíveis mudanças, ao longo dos 4 anos que antecederam o momento das entrevistas em cada empresa, em algumas das prioridades competitivas de produção propostas por Garvin (1993), nas áreas de decisão e em alguns processos de negócios escolhidos.

Quanto às prioridades competitivas de produção, procurou-se levantar quais, dentre as prioridades e subprioridades, foram enfatizadas há 4 anos e quais eram enfatizadas no momento da entrevista. Assim, numa primeira análise, seria possível identificar, se houvessem, mudanças nas prioridades competitivas de produção.

Quanto às áreas de decisão, procurou-se identificar, com uma série de perguntas, a configuração de cada uma das áreas e as mudanças implementadas ao longo do mesmo período de 4 anos (até o momento da entrevista). Com os dois conjuntos de respostas, pôde-se identificar a estratégia de produção realizada em cada empresa, confrontando-se as mudanças nas prioridades competitivas com as mudanças implementadas nas áreas de decisão e buscando-se, desse modo, identificar padrões de comportamento das empresas.

Solicitou-se, ainda, que os entrevistados descrevessem alguns processos de negócios relacionados à produção, mas constatou-se que tal abordagem tem ainda limitada aplicação nas empresas estudadas e pouca informação poderia ser acrescentada aos levantamentos anteriormente realizados sobre prioridades competitivas e áreas de decisão.

As entrevistas constituíram a principal fonte de informação para a pesquisa, mas a observação direta, em visitas às plantas, permitiu a verificação de alguns dos programas colocados em prática pelas empresas. A coleta de dados em fontes secundárias, como artigos publicados em periódicos e as home pages das empresas, foi feita para complementar o conjunto de informações obtido em cada planta.

Em síntese, o método adotado de elaboração de estudos de caso, a partir de entrevistas semiestruturadas com gerentes de produção e da análise de mudanças nos 4 anos que antecederam os momentos das entrevistas, permitiu verificar quais dimensões competitivas foram priorizadas no passado recente e se as mudanças nas áreas de decisão e nos processos de negócios foram compatíveis com as mudanças pretendidas ou alcançadas nas prioridades competitivas, compondo um padrão aparentemente consistente de mudanças em cada empresa.

\section{Estratégia de produção em montadoras de motores}

Nesta seção apresenta-se uma análise comparada das Estratégias de Produção (EPs) adotadas por seis empresas montadoras de motores para automóveis instaladas no Brasil. Todas as empresas estudadas são multinacionais de grande porte que pertencem a corporações que produzem automóveis.

Identificam-se e analisam-se, inicialmente, as prioridades competitivas das seis montadoras. Posteriormente, discorre-se a respeito das 
características observadas nas áreas de decisão estruturais e infraestruturais e apresentam-se as principais ações implementadas recentemente pelas montadoras para atingir os objetivos estratégicos de seus sistemas de produção.

\subsection{Prioridades competitivas}

Como pode ser observado na Tabela 2, as três empresas instaladas no País há mais tempo, as Montadoras A, B e C, atribuem à flexibilidade a maior relevância entre as prioridades. Flexibilidade de mix e de volume são, no entender dos entrevistados, os principais atributos a serem desenvolvidos pelo sistema de produção das empresas, visando fazer da produção um recurso estratégico fundamental para atender às necessidades de seus clientes: as montadoras de automóveis.

Na Montadora C, também foi enfatizada a importância da flexibilidade de produto, ou de outra maneira, da capacidade da empresa em adaptar os produtos às necessidades dos clientes.

As prioridades qualidade, custo e entrega, para essas três fábricas de motores, têm um grau de importância menor, ou seja, utilizando a denominação de Hill (2000), podem ser consideradas como objetivos de desempenho qualificadores.

A ênfase atribuída por essas três empresas à flexibilidade tem origem em fatores externos e internos às suas plantas. Os fatores externos referem-se às demandas exercidas pelas estratégias competitivas de seus clientes, montadoras de automóveis, que, por operarem com ampla variedade de produtos em segmentos de renda diferentes, demandam grande variedade de tipos de motores produzidos, em altos volumes. Ainda referente aos fatores externos, nos últimos anos, as montadoras sofreram forte pressão do mercado para o desenvolvimento de novos motores visando a customização. $\mathrm{O}$ oferecimento de opcionais nos automóveis - direção hidráulica, ar condicionado, etc. - e a possibilidade de abastecer os veículos com mais de um tipo de combustível - bicombustível foram as principais demandas dos consumidores. Em consequência, as fábricas passaram a operar com maior variedade de motores, o que exigiu maior flexibilidade de seus sistemas produtivos.

Os fatores internos às plantas estão relacionados à gestão do sistema de produção propriamente dito. As mudanças ocorridas no mercado nos últimos anos têm exigido que essas fábricas operem com maiores mix de produtos e volumes, a um dado padrão de qualidade e custos. Essas mudanças tornam ainda mais complexa a gestão dos sistemas produtivos, exigindo melhorias em busca da eficiência e eficácia. Há também que se considerar que a produção nessas empresas atingiu volumes próximos à capacidade de produção, operando com baixa capacidade ociosa, o que faz com que o atributo flexibilidade seja valorizado para que o sistema de operações atenda às variações do mercado.

Já a Montadora D, que também atribui à flexibilidade de mix um grau maior de importância, tem a confiabilidade de entrega como sua segunda principal prioridade. Em 2005, essa montadora experimentou um crescimento significativo nas vendas de seus automóveis, aumentando, dessa maneira, a demanda a ser atendida pela fábrica de motores. Nesse período, a produção de motores praticamente dobrou, fazendo com que a empresa passasse a operar com uma capacidade ociosa muito pequena, em torno de $2 \%$. A variedade de motores também aumentou devido à introdução de um novo tipo de motor e das versões bi-combustível para os tipos existentes. Essa combinação de fatores, aumento acentuado da produção e da variedade de modelos e utilização quase total da capacidade de produção, justifica a atenção voltada para a flexibilidade de mix e confiabilidade de entrega.

As Montadoras E e F apresentam comportamento semelhante em relação às prioridades competitivas. Essas duas empresas estão enfatizando o custo e a qualidade como suas principais prioridades. Nesses dois primeiros quesitos, a diferença está na ordem, uma vez que a Montadora E coloca o custo em primeiro lugar e a qualidade em segundo, enquanto a Montadora $F$ inverte essa ordem como se pode observar na Tabela 1.

Essa priorização também pode ser explicada por fatores externos (condições de mercado) e internos

Tabela 2. Síntese das prioridades competitivas.

\begin{tabular}{cccccc}
\hline Montadora & $\mathbf{1}^{\mathbf{a}}$ Prioridade & $\mathbf{2}^{\mathbf{a}}$ Prioridade & $\mathbf{3}^{\text {a }}$ Prioridade & $\mathbf{4}^{\mathbf{a}}$ Prioridade & $\mathbf{5}^{\text {a }}$ Prioridade \\
\hline A & Fv & Fm & E & C/Q & - \\
B & Fm & Fv & Q & E & C \\
C & Fm/Fv & - & C/Q & - & E \\
D & Fm & E & Q & C & Fv \\
E & C & Q & E & Fv & Fm \\
F & Q & C & E & Fm & Fv \\
\hline
\end{tabular}

Fm: Flexibilidade de mix; Fv: Flexibilidade de volume produção; Q: Qualidade; C: Custo de produção; E: Confiabilidade de entrega. 
às plantas. A Montadora $\mathrm{E}$ não tem alcançado um crescimento de vendas de automóveis como antes planejado pela organização. Isto se reflete diretamente nas operações internas da planta de motores, fazendo com que ela opere com uma capacidade de produção muito aquém de sua capacidade. Enquanto outras medidas estão sendo implementadas para ampliar suas vendas, as atenções na produção estão centradas na prioridade custo (redução de custos) e na utilização eficiente de alguns fatores de produção para diminuir os efeitos nos resultados financeiros de operar com grande capacidade ociosa. Deve-se destacar que todos os esforços no sentido do custo não podem afetar a qualidade, em suas diversas dimensões, pois esta tem um papel importante na estratégia competitiva da montadora de veículos.

A Montadora F, por sua vez, prioriza a qualidade, em primeiro lugar, e custo em segundo lugar. Embora estas duas primeiras prioridades sejam as mesmas da Montadora E, invertendo-se apenas a ordem, os fatores externos e internos que justificam tal priorização são diferentes. A Montadora F vende seus motores apenas para o mercado externo, mais especificamente para clientes na Europa, nos Estados Unidos e na África do Sul. Esses mercados possuem maior estabilidade de demanda, especialmente se comparados ao brasileiro, o que favorece (ou facilita) o gerenciamento da produção. Além disso, a empresa oferece um número reduzido de modelos, o que também contribui para a redução da complexidade da gestão do sistema de produção. Semelhante ao que acontece com a Montadora E, a Montadora F opera com um nível de ociosidade significativo e, portanto, com baixa pressão por melhor desempenho sobre as prioridades flexibilidade e confiabilidade de entrega. Canaliza assim suas iniciativas para as prioridades qualidade e custo, até o momento em que decisões no nível da estratégia de negócio sejam eventualmente tomadas e modifiquem as exigências para a produção.

\section{2 Áreas de decisão e principais ações}

As prioridades competitivas refletem necessidades da estratégia competitiva e apontam para determinados objetivos a serem atingidos pelo sistema produtivo. Para se alcançar esses objetivos, é necessário o desenvolvimento de um padrão de ações relacionadas às áreas de decisão estruturais e infraestruturais. As Tabelas 3 e 4 apresentam uma síntese das informações relativas às áreas de decisão estruturais e infraestruturais das montadoras de motores estudadas.

As Montadoras A, B e C, que estão priorizando a flexibilidade de mix e de volume, adotam estratégias de produção com semelhanças e diferenças nas áreas estruturais. As Montadoras B e C concentram sua produção em uma única planta, já a Montadora A fabrica motores em duas plantas. A fábrica da
Montadora C se encontra localizada na mesma unidade em que monta seus automóveis, enquanto a Montadora B, que possui três unidades montadoras de veículos, localiza sua fábrica de motores junto a uma delas. A Montadora A possui uma planta, a mais antiga, junto à unidade que monta alguns de seus modelos de automóveis e outra planta, distante da montadora de automóveis, focada na fabricação de motores.

As três empresas possuem alta capacidade de produção e produzem ampla variedade de modelos que se diferenciam pela potência, tipo de combustível e acessórios. A Montadora B se destaca por apresentar a maior capacidade instalada. As três empresas possuem níveis de automação e produtos com conteúdo tecnológico semelhante e diferem quanto aos graus de integração vertical de suas plantas. A Montadora B, entre todas as empresas estudadas, é a mais verticalizada, pois funde o bloco do motor, usina todo o bloco e também o virabrequim e o cabeçote. A Montadora C, por sua vez, compra o bloco de fornecedores, mas usina o bloco, o virabrequim e o cabeçote. Já a Montadora A apenas usina o bloco do motor e compra o virabrequim e o cabeçote já acabados.

Nas áreas infraestruturais, de maneira geral, também é possível observar semelhanças e diferenças. As três empresas possuem sistemas de informação para PCP desenvolvidos a partir da lógica do ERP, possuem EDI para conexão com a montadora de veículos e também com os fornecedores, têm uma política da qualidade corporativa, seus sistemas da qualidade são certificados, utilizam as principais ferramentas básicas e gerenciais para controle e melhoria da qualidade e avaliam seus fornecedores tendo como principal referência os requisitos das normas da qualidade. Quanto à organização do trabalho, utilizam os conceitos de célula, trabalho em equipe, programas de sugestão, investem em treinamento para os funcionários do chão de fábrica, etc. Todas essas empresas têm uma estrutura bem desenvolvida para o desenvolvimento de produtos, com um grande contingente de engenheiros e projetistas. Nesse quesito, deve-se destacar que existem diferenças entre as empresas no que tange à autonomia tecnológica das unidades locais em relação às matrizes no exterior e, também, quanto ao grau de integração das equipes de engenharia com as respectivas unidades de desenvolvimento de produto localizadas no exterior.

Quanto à gestão de suprimentos, as empresas têm em comum o fato de trabalhar com um grande número de fornecedores (em sua maioria de grande porte e de boa capacidade tecnológica), não possuir fornecedores exclusivos, utilizar EDI para seu fluxo de informação e se relacionar apenas com o primeiro nível da cadeia. Entretanto, diferenças substantivas 


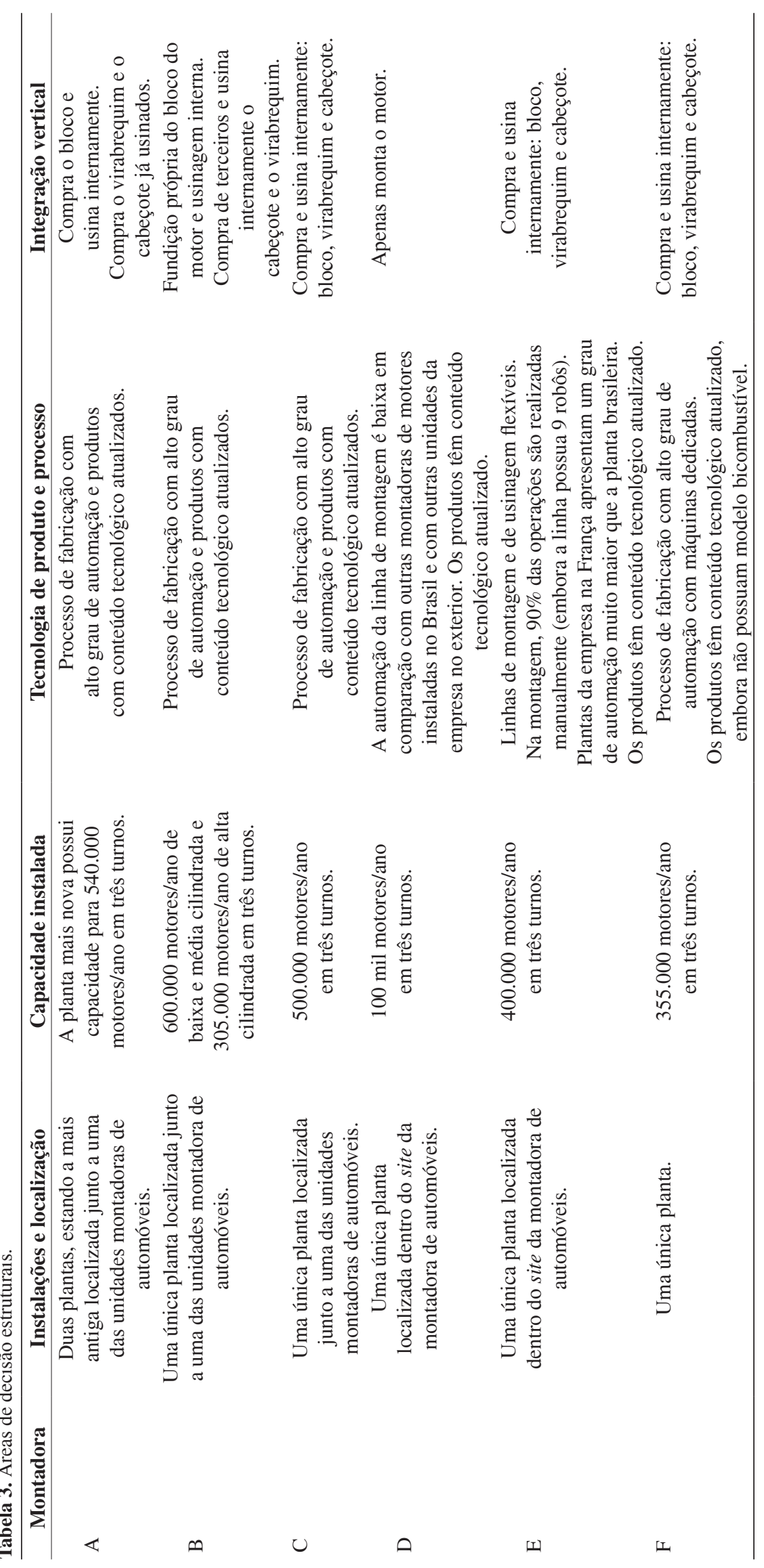




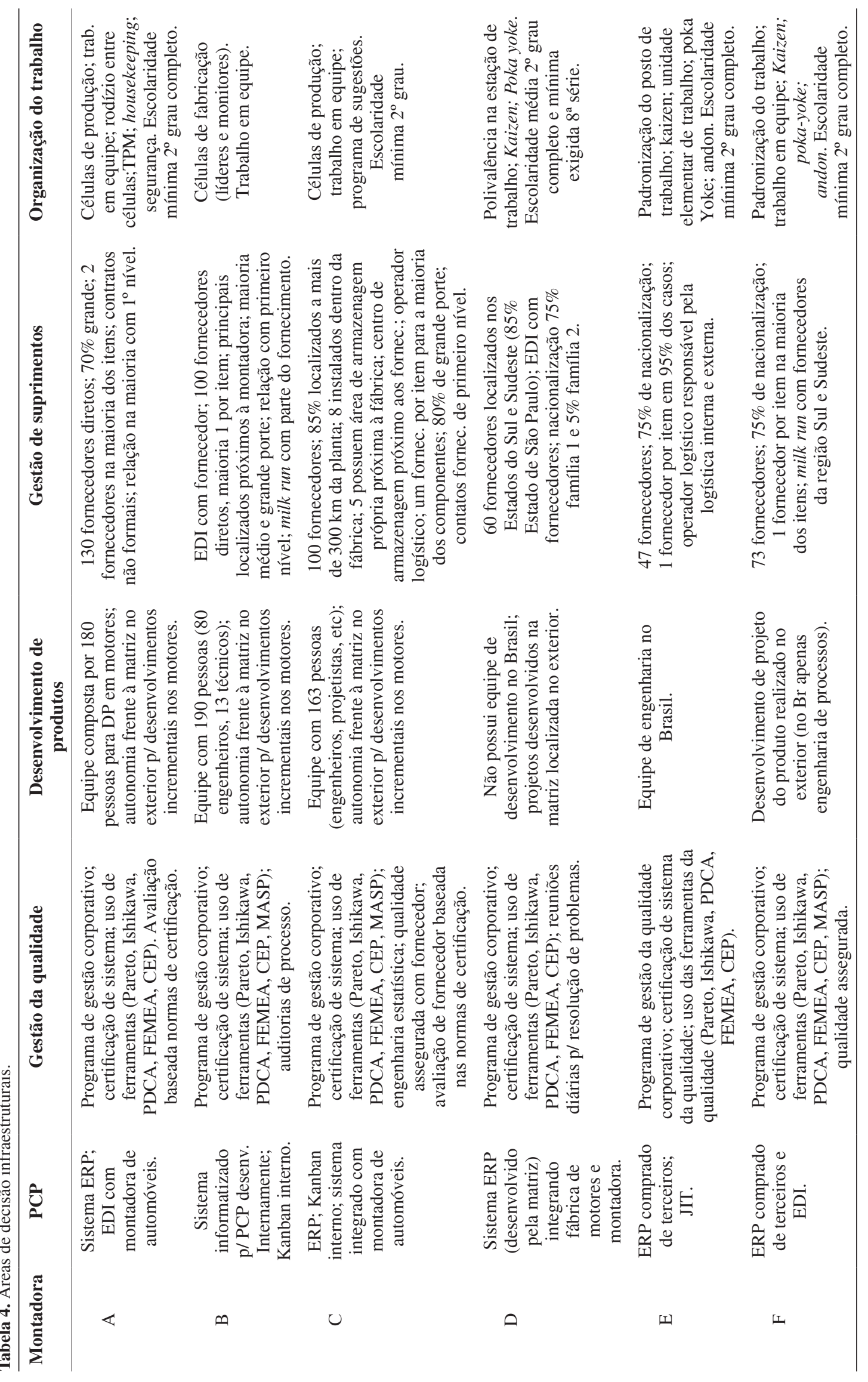


também podem ser observadas na estrutura e na gestão das cadeias de fornecimento. A Montadora C, por exemplo, se encontra localizada distante do principal centro produtor de autopeças, que é o Estado de São Paulo, exigindo toda uma estrutura logística diferenciada que envolve um centro de recebimento de materiais em São Paulo e armazéns de alguns fornecedores próximos a sua planta em outro Estado da Federação. Na Montadora A, é importante destacar que ela trabalha com um número de fornecedores $30 \%$ maior do que o das outras duas montadoras, não estabelece contratos formais e para a maioria dos itens atua em paralelo com dois fornecedores.

Alguns movimentos no sentido de promover mudanças podem ser observados nessas empresas. No que diz respeito às áreas estruturais, a Montadora B está desenvolvendo ações visando reduzir o seu grau de verticalização. A empresa deverá encerrar as atividades de sua fundição, terceirizando essa atividade. Além disso, investiu em máquinas e equipamentos visando atender necessidades das novas gerações de motores que está fabricando. A Montadora C, por sua vez, terceirizou a usinagem de peças de menor importância para o motor, enquanto que a Montadora A promoveu algumas melhorias no processo de fabricação visando melhorar a qualidade e reduzir custos (teste a frio dos motores).

Ainda no que se refere às áreas infraestruturais, a Montadora A tem investido na melhoria da logística por meio da racionalização do transporte (carga) e do aumento dos contatos com os fornecedores. A Montadora B investe no desenvolvimento de novos produtos, motores de nova geração $\left(3^{\mathrm{a}}\right)$ que, segundo o entrevistado, apresentam ganhos de potência, autonomia e economia. Na Montadora C, também devem ser destacados os esforços que a empresa vem desenvolvendo para atender às necessidades do mercado, o que tem gerado constantes alterações no projeto dos produtos e ampliado o mix.

A Montadora $\mathrm{D}$, que está priorizando flexibilidade de mix, em primeiro lugar, e confiabilidade de entrega em segundo, possui uma estratégia de produção diferenciada entre as seis empresas estudadas no que diz respeito às áreas estruturais. A Montadora D concentra a produção de motores em uma única planta, na mesma unidade em que monta seus automóveis. Sua capacidade de produção é reduzida, frente às outras montadoras, entretanto é compatível com a participação de mercado que a empresa possui. Entre as empresas estudadas é a mais terceirizada, pois não fabrica nenhum componente, apenas monta o motor. A linha de montagem tem um menor grau de automação quando comparada com outras montadoras instaladas no Brasil e com a unidade de motores da empresa em seu país sede. No que diz respeito à tecnologia de produto, essa empresa apresenta o mesmo padrão tecnológico das demais montadoras, embora possua um mix de produtos limitado se comparado com as Montadoras A, B e C, por exemplo.

Nas áreas infraestruturais, a Montadora D utiliza um sistema ERP desenvolvido internamente para planejamento e controle da produção, tem um programa da qualidade corporativo, possui certificação do sistema da qualidade e utiliza as diversas ferramentas da qualidade para controle e melhoria da qualidade de seus produtos. $\mathrm{Na}$ área de suprimentos a empresa trabalha com cerca de 60 fornecedores por tipo de motor, localizados predominantemente no Estado de São Paulo. A comunicação com os fornecedores é feita por intermédio de um sistema EDI. A organização do trabalho na linha prioriza o trabalho manual, apenas $20 \%$ dos processos são automatizados, e utiliza diversas ferramentas e conceitos inspirados no sistema Toyota de Produção (Lean Manufacturing/ Produção Enxuta).

A Montadora D também vem promovendo mudanças em suas áreas estruturais, sendo a mais importante no momento a ampliação da capacidade de produção em $30 \%$, por meio da introdução de novos equipamentos e mudanças na organização do trabalho na linha. Nas áreas infraestruturais dois aspectos merecem destaque. O primeiro é o intenso esforço que a empresa vem desenvolvendo para aumentar o índice de nacionalização de seu fornecimento. Dois dos principais resultados desse processo são a redução de custos e o aumento da flexibilidade (agilidade). $\mathrm{O}$ segundo é o desenvolvimento de sua área de projeto do produto aqui no Brasil. Está prevista a contratação de um número significativo de engenheiros para os próximos anos.

As Montadoras E e F têm como principais prioridades qualidade e custo. As duas empresas possuem, cada uma, uma única planta no Brasil e têm capacidade de produção, nível de automação e produtos de tecnologia semelhantes. Quanto à verticalização, as duas também apresentam semelhanças. Três das principais partes do motor, bloco, virabrequim e cabeçote, são comprados de terceiros e usinados internamente.

Nas áreas infraestruturais, tanto a Montadora E quanto a Montadora F possuem um sistema de gestão da produção desenvolvido, tendo como referência o Sistema Toyota de Produção. Utilizam, dessa forma, um conjunto de conceitos e ferramentas destinado à padronização de operações, aumento do fluxo de produção e melhoria contínua da qualidade. Possuem também seus sistemas de informação ERP para planejamento da produção e ainda utilizam conceitos do JIT e kanban. No que diz respeito à gestão da qualidade, assim como as outras empresas estudadas, possuem um programa de qualidade corporativo, seus sistemas da qualidade são certificados e as ferramentas da qualidade têm uso disseminado na empresa. A organização do trabalho no chão de 
fábrica nas duas empresas é caracterizada pela utilização de recursos inspirados no modelo japonês (trabalho em equipe, polivalência, padronização de tarefas, rodízio de funções, etc.). No que diz respeito à gestão de suprimentos, ambas possuem um índice de nacionalização semelhante e atuam com um fornecedor por item. Os fornecedores concentram-se (a maioria) no Estado de São Paulo e entregam os componentes com garantia da qualidade, sendo a logística de entrega de responsabilidade de terceiros.

O sistema de gestão baseado no Lean Manufacturing foi introduzido recentemente por essas duas empresas. Entretanto, deve-se salientar que na Montadora F o sistema parece estar mais consolidado, pois foi implantado há mais tempo. A Montadora E, em 2005, concentrou esforços no sentido de reduzir drasticamente o nível de seus estoques e de efetivar o uso das diversas ferramentas que constituem o modelo de gestão adotado (kaisen, TPM, FMEA, PDCA, etc), visando melhorar qualidade e reduzir custos. A Montadora F, por sua vez, investe no aumento da nacionalização do fornecimento e na gestão da cadeia de suprimentos, pois avalia que $70 \%$ dos custos são externos à fábrica. Assim, estão realizando reuniões com os fornecedores e oferecendo treinamento nas ferramentas do Lean Manufacturing, visando reduzir estoques, desperdícios e lead time.

A Tabela 5 sintetiza algumas das principais ações que estão sendo implementadas pelas empresas estudadas, visando atingir os níveis de desempenho exigidos por suas estratégias.

Finalizando esta análise, é importante destacar as semelhanças e as diferenças dentro dos seguintes grupos estratégicos de empresas: Estabelecidas (Montadoras A, B e C - no mercado brasileiro há mais de 20 anos) e Entrantes (Montadoras D, E e F - no mercado brasileiro a partir de meados da década de 90).

No grupo das Estabelecidas, observa-se que as empresas montadoras de veículos adotam estratégias competitivas semelhantes, participando mais ou menos da mesma forma nos diversos segmentos de mercado da indústria automobilística e atribuindo a suas fábricas de motores papéis também similares. Desse modo não se deve estranhar, ao se analisar as respectivas estratégias de produção, que as prioridades competitivas de produção ao longo dos últimos anos sejam semelhantes. Entretanto, é também possível observar diferenças significativas nas estratégias de produção, demarcadas por algumas áreas de decisão estruturais e infraestruturais - especialmente grau de verticalização e gestão de suprimentos. As trajetórias passadas das empresas (quanto às estratégias de produção adotadas, às estruturas de produção e às competências experimentadas e acumuladas) condicionam fortemente as iniciativas presentes e futuras. Desse modo, por exemplo, os movimentos de terceirização das Montadoras B e C podem ser considerados ainda lentos em comparação ao da Montadora A. Também, no que diz respeito ao relacionamento com fornecedores e à gestão de suprimentos, as três empresas analisadas adotam esquemas distintos. A Montadora $\mathrm{C}$ procura ter relacionamentos de longo prazo com fornecedores de grande porte, localizados a uma distância superior a $350 \mathrm{~km}$. A Montadora B adota praticamente a mesma política, mas numa estrutura em que os fornecedores estão localizados mais próximos de algumas de suas plantas. Já a Montadora A não emprega com tanto rigor o princípio de relacionamento de longo prazo e procura explorar as vantagens que pode auferir da relação com fornecedores de menor porte e localizados próximos à planta de motores.

No grupo das entrantes, observa-se inicialmente que as estratégias competitivas das Montadoras E e D são semelhantes, pois mantêm, por enquanto pelo menos, um mix de produtos relativamente pequeno, dirigido aos mesmos segmentos do mercado brasileiro e do Mercosul. Entretanto suas estratégias de produção (e as respectivas trajetórias) são bastante distintas. A Montadora D é a mais terceirizada das empresas analisadas, enquanto a Montadora E possui grau de integração vertical semelhante ao da Montadora C, superior ao das Montadoras D e A, mas inferior ao da Montadora B. Além disso, suas prioridades competitivas de produção são diferentes, basicamente porque os índices de capacidade ociosa são muito distintos. Aparentemente a Montadora D obteve vantagens com a implantação posterior (no tempo) de sua planta de motores e com a estratégia de acréscimos incrementais em sua capacidade de produção. A Montadora D avança também de forma gradual em seus índices de nacionalização e na formação local de uma estrutura de desenvolvimento de produto/processo.

Já a Montadora $\mathrm{F}$ possui estratégia competitiva muito diferente das demais empresas (incluindo as duas entrantes), produzindo um mix reduzido de motores, apenas para o mercado externo. Sua estratégia de produção pode ser comparada à da Montadora E. As prioridades competitivas de produção dessas empresas são semelhantes, fato que pode ser explicado pela semelhança nas relações entre capacidade e volume de produção. Ambas vêm investindo na implementação do modelo de produção enxuta, visando principalmente melhorar a eficiência de seus processos de produção e com isso reduzir custos e melhorar qualidade.

\section{Considerações finais}

A pesquisa realizada possibilitou a identificação e comparação das estratégias de produção adotadas por seis das principais empresas produtoras de 
Tabela 5. Principais movimentos realizados pelas fábricas de motores.

\begin{tabular}{|c|c|}
\hline Montadora & Principais movimentos \\
\hline $\mathrm{A}$ & $\begin{array}{l}\text { Melhorias da logística de fornecimento e entrega; aumento dos contatos com os fornecedores. } \\
\text { Melhorias incrementais no processo de fabricação, visando melhorar a qualidade e reduzir custos. }\end{array}$ \\
\hline B & $\begin{array}{l}\text { Redução do grau de verticalização; investimento em máquinas e equipamentos } \\
\text { para as novas gerações de motores; desenvolvimento de novos produtos. }\end{array}$ \\
\hline $\mathrm{C}$ & $\begin{array}{l}\text { Terceirização da usinagem de peças de menor importância } \\
\text { para o motor; constantes alterações no projeto dos produtos ampliando mix. }\end{array}$ \\
\hline $\mathrm{D}$ & $\begin{array}{l}\text { Ampliação da capacidade de produção; aumento no índice de } \\
\text { nacionalização de seu fornecimento; desenvolvimento da área de projeto do produto no Brasil. }\end{array}$ \\
\hline $\mathrm{E}$ & $\begin{array}{l}\text { Implementação de sistema de gestão baseado no Lean Manufacturing; redução de estoque; } \\
\text { efetivação do uso de ferramentas de gestão para redução de custos e melhoria da qualidade. }\end{array}$ \\
\hline $\mathrm{F}$ & $\begin{array}{l}\text { Implementação de sistema de gestão baseado no Lean Manufacturing; } \\
\text { aumento da nacionalização do fornecimento e melhorias na gestão da cadeia de fornecimento. }\end{array}$ \\
\hline
\end{tabular}

motores para automóveis instaladas no Brasil. Possibilitou, também, a verificação das práticas adotadas pelas empresas, promovendo a discussão de temas relevantes, tanto do ponto de vista teórico quanto prático, para continuidade de produção de conhecimento em uma linha de pesquisa sobre estratégia de produção na indústria automobilística.

A pesquisa destacou ainda a relevância acadêmica e econômica do tema ao mostrar quão importante é o papel da produção no desempenho de empresas pertencentes a um setor (indústria automobilística) com peso expressivo na indústria nacional e, ainda, como são úteis e importantes na tomada de decisão os conceitos desenvolvidos no campo (teórico) da estratégia de produção. Os avanços nesse campo dependem desse confronto, se possível constante, entre teoria e prática, como este artigo procura ilustrar.

De modo geral, a pesquisa possibilitou identificar diferenças e semelhanças nas estratégias adotadas e nas trajetórias (sequências de decisões e ações) implementadas, que apresentam impactos significativos nos resultados por elas obtidos. A pesquisa confirma a importância da discussão sobre: consistência/ coerência entre prioridades competitivas de produção e áreas de decisão estruturais e infraestruturais; grupos estratégicos; combinações possíveis entre estratégias competitivas e estratégias de produção; e ainda sobre as próprias trajetórias de estratégias de produção (sequências de estratégias de produção) das organizações.

As análises feitas derivaram do emprego de um método consistente de identificação das estratégias de produção das empresas (das unidades de produção de motores) que possibilita o levantamento das prioridades competitivas de produção e das mudanças implementadas nas diversas áreas de decisão no passado recente. Uma análise mais abrangente dos processos de negócios implementados em cada organização - que não pôde ser realizada neste trabalho - poderia trazer ainda mais detalhes sobre as estratégias adotadas, complementando e eventualmente confirmando (ou não) o que foi aqui relatado.

Cabe ainda aqui recuperar as principais conclusões desta pesquisa, apresentadas agora de maneira genérica, com base em evidências dos estudos de caso realizados. Deve-se, entretanto, destacar que a base empírica nesta pesquisa que sustenta as conclusões a seguir sumarizadas é bastante limitada, embora representativa do segmento industrial estudado: o segmento de fabricantes de motores para automóveis localizado no Brasil.

a) Foram identificadas diferentes combinações de estratégias competitivas e estratégias de produção, mesmo se comparadas empresas que fazem parte de um mesmo grupo estratégico (que adotam estratégias competitivas semelhantes).

b) Diferentes estratégias competitivas e diferentes estratégias de entrada no mercado brasileiro estabelecem requisitos e pressões diferenciadas sobre a produção e conduzem à adoção de distintas estratégias de produção. Assim, por exemplo, a definição de um relativo baixo grau de integração vertical vai exigir um esforço relativamente maior para gestão e a coordenação da cadeia de suprimentos.

c) As prioridades competitivas da produção são definidas em função de fatores externos - de mercado - e em função de fatores internos relacionados à situação e configuração dos recursos acumulados. Assim, por exemplo, uma empresa prioriza flexibilidade de mix porque o mercado demanda diferentes modelos de motores, enquanto outra prioriza redução de custos porque está com compacidade ociosa de produção. As prioridades competitivas de produção são definidas, então, em função das estratégias competitivas (que refletem fatores 
de mercado como, por exemplo, demanda mais ou menos aquecida) e das características das áreas de decisão (que refletem os recursos acumulados e as pressões decorrentes de determinada trajetória).

d) No período examinado, as empresas estabelecidas estavam priorizando objetivos de flexibilidade em função da ampliação do mix de produtos e do mix de produção, enquanto as empresas entrantes estavam priorizando objetivos de qualidade e de custos, mas com variações em função das estratégias de entrada e dos mercados atendidos.

e) As prioridades competitivas de produção variam ao longo do tempo em função de diversos fatores, como os mencionados nos itens anteriores, mas, em determinados momentos, podem não estar vinculadas ou diretamente relacionadas às prioridades de longo prazo estabelecidas nas estratégias competitivas ou à alguma sequência genérica de prioridades - como a estabelecida no modelo do cone de areia (FERDOWS; DE MEYER, 1990), por exemplo. Ou seja, uma empresa que se diferencie pela qualidade de conformação não necessariamente terá esse objetivo como o primeiro, em todos os momentos, dentre as suas prioridades competitivas de produção. E nem todas as empresas irão seguir uma ordem predeterminada de prioridades como, por exemplo, Q, E, C, F.

f) Mudanças nas prioridades competitivas de produção (e nas estratégias competitivas e de entrada, eventualmente) e as correspondentes medidas implementadas nas áreas de decisão compõem as estratégias de produção e, ao longo do tempo, marcam os movimentos e as trajetórias das estratégias adotadas pelas empresas.

g) Prioridades competitivas e áreas de decisão formam um todo coeso com papel importante na estratégia competitiva de uma empresa fabricante de motores.

h) Mudanças nas prioridades e nas áreas decisão requerem grandes esforços, investimentos e prazos para alcançar os resultados esperados e por isso coerência, consistência e persistência são importantes.

i) Prioridades competitivas de produção afetam áreas de decisão, e áreas de decisão estruturais condicionam áreas de decisão infraestruturais. Chama a atenção na pesquisa o quanto as decisões sobre localização e sobre integração vertical condicionaram as políticas e medidas relacionadas a Compras/Suprimentos.

j) No setor, como as empresas estão submetidas às mesmas condições de mercado e analisam os movimentos umas das outras, há uma tendência de movimentos estratégicos convergentes sucederem períodos em que uma ou mais empresas adotam estratégias diferenciadas. Em períodos relativamente curtos de tempo, alguma empresa pode assumir um comportamento diferente ou inovativo, mas, logo a seguir, dependendo dos resultados, ou tal comportamento é imitado pelas demais, ou a própria empresa retorna à condição anterior, quando os resultados não são bons. Pelo que se pôde observar, as empresas adotam estratégias que tendem a se assemelhar a longo prazo. $\mathrm{O}$ comportamento das montadoras em relação ao grau de integração vertical pode ilustrar tal afirmação. Esta hipótese de comportamento "pendular" das estratégias adotadas - ora afastando-se, ora aproximando-se - requer, entretanto, cuidadosos estudos longitudinais para ser efetivamente confirmada ou rejeitada.

A maioria desses pontos é coincidente ou convergente com resultados de grande parte das pesquisas sobre estratégia de produção. Alguns - como os apresentados nos itens (b), (c), (d) e (f) -, além de convergentes com a literatura, sugerem temas que ainda não foram suficientemente estudados. Outros - como o mencionado no item (e) - podem ser considerados polêmicos e ainda requerem investigações adicionais. Finalmente, o resultado indicado no item (j) ainda precisaria ser confirmado com pesquisas longitudinais - que abrangessem períodos de tempo maiores - no segmento das montadoras de motores e em outros setores.

\section{Referências}

ADAMIDES, E. D.; POMONIS, N. The co-evolution of production and supply chain decisions, and the emergence of manufacturing strategy. International Journal of Production Economics, v. 121, p. 301-312, 2009. http://dx.doi.org/10.1016/j.ijpe.2006.11.025

AMERICAN PRODUCTIVITY \& QUALITY CENTER. Disponível em: <http://www.apqc.org >. Acesso em: 01 out. 2008.

ANDERSON, J. C.; CLEVELAND, G.; SCHROEDER, R. G. Operations strategy: a literature review. Journal of Operations Management, v. 8, n. 2, p. 133-158, April 1989. http://dx.doi. org/10.1016/0272-6963(89)90016-8

BOYER, K. K.; SWINK, M.; ROSENZWEIG, E. D. Operations strategy research in the POMS journal. Production and Operations Management, 
v. 14, n. 4, p. 442-449, 2005. http://dx.doi. org/10.1111/j.1937-5956.2005.tb00232.x

COHEN, M. A.; LEE, H. L. Manufacturing Strategy Concepts and Methods. In: KLEINDORFER, P. R. The Management of Productivity and Technology in Manufacturing. New York: Plenum Press, 1985. cap. 5, p. 153-186.

CORIAT, B.; DOSI, G. The nature and accumulation of organizational competences / capabilities. Revista Brasileira de Inovação, v. 1, n. 2, p. 275- 326, 2002.

DANGAYACH, G. S.; DESHMUKH, S. G. Manufacturing strategy - literature review and some issues. International Journal of Operations \& Production Management, v. 21, n. 7, p. 884-932, 2001. http:// dx.doi.org/10.1108/01443570110393414

FERDOWS, K.; DE MEYER, A. Lasting improvements in manufacturing performance: in search of a new theory. Journal of Operations Management, v. 9, n. 2, p. 168-184, 1990. http://dx.doi. org/10.1016/0272-6963(90)90094-T

FINE, C. H.; HAX, A. C. Manufacturing Strategy: A Methodology and an Illustration. Interface, v. 15, n. 6, p. 28-46, 1985.

GARVIN, D. A. Manufacturing strategy planning. California Management Review, v. 35, n. 4, p. 85-106, 1993.

GARVIN, D. A. The process of organization and management. Sloan Management Review, v. 39, n. 4, p. 33-51, 1998.

GYANPAH, K. A.; BOYE, S. S. Operations strategy in an emerging economy: the case of the Ghanaian manufacturing industry. Journal of Operations Management, v. 19, n. 1, p. 59-79, January 2001. http://dx.doi.org/10.1016/S0272-6963(00)00046-2

HAYES, R. et al. Operations, strategy, and technology - pursuing the competitive edge. New York: John Wiley \& Sons, Inc, 2005.

HAYES, R.; PISANO, G. P. Beyond Word-Class: The New Manufacturing Strategy. Harvard Business Review, v. 72, n. 1, p. 77-86, 1994.

HAYES, R.; WHEELWRIGHT, S. C. Restoring our competitive edge: competing through manufacturing. United States of America: John Wiley \& Sons, 1984.

HAYES, R.; WHEELWRIGHT, S. C.; CLARK, K. B. Dynamic manufacturing: creating the learning organization. New York: The Free Press, 1988.

HILL, T. Manufacturing strategy: text and cases. 2th ed. United States of America: Richard D. Irwin Inc., 1994.

HILL, T. Operations management - strategic context and managerial analysis. London: MacMillan Press Ltd., 2000.

HÖRTE, S. A.; LINDBERG, P.; TUNÄLV, C. Manufacturing strategic in Sweden. International Journal of Production Research, v. 25, n. 11, p. 1573-1586, 1987.
MILL, J.; PLATTS, K.; GREGORY, M. A framework for the design of manufacturing strategy processes - A contingency approach. International Journal of Operations \& Production Management, v. 15, n. 4 , p. 17-49, 1995. http://dx.doi. org/10.1108/01443579510083596

MINTZBERG, H. Opening up the definition of strategy. In: QUINN, J. B.; MINTZBERG, H.; JAMES, R. M. The strategy process: concepts, contexts and cases. London: Prentice-Hall, 1988. p. 13-20.

MOLLONA, E. A competence view of firm as resource accumulation systems: a synthesis of resource-based and evolutionary models of strategy-making. In: MORECROFT, J. D. W.; SANCHEZ, R.; HEENE, A. Systems perspectives on resources, capabilities, and management processes. Amsterdam: Pergamon, 2002. cap. 6, p. 93-126.

PLATTS, K. W.; MILL, J. F.; BOURNE, M. C.; NEELY, A. D.; RICHARDS, A. H.; GREGORY, M. J. Testing manufacturing strategy formulation processes. International Journal of Production Economics, v. 56-57, p.517-523, 1998. http://dx.doi.org/10.1016/ S0925-5273(97)00134-5

SÄFSTEN, K.; WINROTH, M.; STAHRE, J. The content and process of automation strategies. International Journal of Production Economics, v. 110, n. 1, p. 25-38, 2007. http://dx.doi.org/10.1016/j.ijpe.2007.02.027

SKINNER, W. Manufacturing - missing link in corporate strategy. Harvard Business Review, v. 47, n. 3, p. 136-145, 1969. http://dx.doi. org/10.1111/j.1937-5956.1996.tb00381.x

SKINNER, W. Manufacturing - the formidable competitive weapon. New York: John Wiley \& Sons, 1985. http://dx.doi.org/10.1016/j.jom.2006.10.008 SKINNER, W. Manufacturing strategy on the "S" curve. Production and Operation Management, v. 5, n. 1, p. 3-14, 1996.

SKINNER, W. Manufacturing strategy: the story of its evolution. Journal of Operations Management, v. 25, n. 2, p. 328-335, 2007.

SLACK, N. Vantagem competitiva em manufatura. São Paulo: Atlas, 1993.

SLACK, N.; LEWIS, M. Operations Strategy. New York: Prentice Hall, 2001.

SWAMIDASS, P. M.; NEWELL, W. T. Manufacturing strategy, environmental uncertainly and performance: a path analytical model. Management Science, v. 33, n. 4, p. 509-524, 1987. http://dx.doi.org/10.1287/ mnsc.33.4.509

WHEELWRIGHT, S. C. Manufacturing Strategy: Defining the Missing Link. Strategy Management Journal, v. 5, p. 77-91. 1984. http://dx.doi.org/10.1002/smj.4250050106 
